\title{
Health Risk Assessment of Soil Heavy Metals in Agricultural Regions
}

\author{
Danasekara D. R. A. K. \\ Department of Geography, University of Kelaniya, Sri Lanka \\ apsaradanasekara@gmail.com
}

\begin{abstract}
Soil is one of the essential and dynamic natural resource on Earth. All living beings and eco system depend on the soil. Soil health is a measure of soil functions. Consequently, it is the optimum status of the soil's biological, physical and chemical functions. Healthy soils can sustain plant and animal productivity and soil biodiversity. It is the foundation of agriculture and an essential resource to ensure human needs. Furthermore, recently soil health is declining due to the several agricultural patterns in the world. Agriculture is the dominant economic practice in Sri Lanka. Hence soil health is very important to increase the food production in Sri Lanka. The main objective of this research is identify the soil health in rural agricultural areas in Sri Lanka. To achieve the target divided selected study area in to seven land use patterns and obtain soil samples in each sites. Soil organic carbon (SOC) is a key indicator of soil health. Hence test the SOC percentage in the study area to identify the soil health of rural areas according to the several land use patterns in the area. The results have revealed that depletion of SOC due to the various land use patterns in the study area. Consequently, these changes have resulted in negatively affecting agricultural productivity and provision of ecosystem services in rural agricultural areas in Sri Lanka. Conservation agriculture, land use conservation, use of organic amendment, weed control methods are some dominant management practices to increase SOC in the soil. Additionally, public awareness is very important in rural agricultural areas in Sri Lanka to increase the soil health and agricultural productivity.
\end{abstract}

Keywords: Soil health, rural agricultural area, Sri Lanka

\section{Introduction}

Soil is a living organism (Fitz Patrick, 1983). It is the most valuable natural resource after the water resource in the world. It supports all terrestrial life and is involved in the regulation and provision of many key ecosystem services that are essential to the environment and to human health and well - being. Soil formation is not a simple process. Because regeneration of soil through chemical and biological weathering of underlying rock requires geological time (Huber et al.2001).

Soil health is the significant factor of soil resource. Soil health is the continued capacity of soil to function as a vital living ecosystem that sustains plants, animals and humans, and connects agricultural system and provide sustainable management to the earth (Lehmann et al.2020). Soil health focus on the continued capacity of a soil to sustain plant growth and maintain its functions regardless of the fitness for any certain purposes (Pankhurst et al.1997). Several definitions of soil health have been proposed during the last decades. Historically, the term soil quality described the status of soil as related to agricultural productivity or fertility (Singer et al.2000). In the 1990s, it was proposed that soil quality was not limited to soil productivity but instead expanded to encompass interactions with the surrounding environment, including the implications for human and animal health.

The soil, which is a limited resource is under grate threat due to high population growth, agricultural and industrial advancement that exist today. The Status of the World's Soil Resources report presented in 2015 by the Food and Agriculture Organization of the United Nations (FAO) and the Intergovernmental Technical Panel on Soil (ITPS) identified ten major threats to the world's soils. Soil erosion, loss of soil organic carbon and biodiversity, pollution, acidification, salinization, nutrient imbalance, compaction, sealing and water logging are major pressures on soil health and limit their capacity to provide these key ecosystem services for human well - being. Therefore, recently the world has become more concerned about soil health.

Healthy soils are the foundation of the food system. Soil is the basis for agriculture and the medium in which nearly all food - producing plants grow. Healthy soils produce healthy crops that in turn nourish people and animals. Indeed, soil quality is directly linked to food quality and quantity.

With a global population that is projected to exceed 9 billion by 2050 , compounded by competition for land and water resources and the impact of climate change, our current and future food security hinges on our ability to increase yields and food quality using the soils. So healthy soil is more important to obtain high yields from agricultural lands and food security in the World.

Soil organic Carbon is one of the best indicator to identify the soil health. Because after the oceans, soil is the largest active carbon store and one cubic meter of soil can store up to 600 liters of water, allowing crops to grow even during dry periods. (Global Assessment of Soil Pollution, 2021). Globally, soil contains approximately $2344 \mathrm{Gt}$ of organic carbon (OC), which is the largest terrestrial pool of organic carbon (Ngatia, 2021).

Soil organic carbon (SOC) is the carbon associated with soil organic matter. Although it is a measureable component of soil organic matter. Due to the high population natural vegetation convert in to agricultural land cause to decline SOC in the soil. Consequently, these changes have resulted in depletion of SOC stock, thereby negatively affecting 
agricultural productivity and provision of ecosystem services Final result of this process is depletion of soil health. So it is very important to identify the soil health in rural agricultural areas. Because agricultural productivity and soil health integrate each other.

\section{Methodology}

Soil organic carbon is critical to the stabilization of soil structure, retention and release of plant nutrients and maintenance of water - holding capacity, thus making it a key indicator not only for agricultural productivity, but also the environmental resilience. Soil organic carbon is a measurable component of soil organic matter. Soil organic carbon refers only to the carbon component of organic compounds. Although SOC is the best biological indicator of soil health. Soil carbon levels can be determined by factors such as rainfall, temperature, vegetation and soil type and reach equilibrium values associated with individual systems and locations. In general, microbial activities are high due to the high temperature in the dry zone. Therefore, organic matter decomposes quickly.

We were Grama Niladhari Division is one of rural agricultural area in Kandy District, Sri Lanka. Besides there are several land use patterns in the area. The mean annual rainfall of this area is about $200 \mathrm{~mm}$. Main rainfall pattern is northeast monsoon and average temperature is between $26^{\circ}$ $\mathrm{C}-28^{\circ} \mathrm{C}$. Major soil types in the area are reddish brown earth soil, immature brown loam soil. By considering these factors we were GND selected as the study area.

The study area was divided into seven land units from the total land area of $7.7957 \mathrm{~km}^{2}$ under the judgment sampling method according to the most common human activities in the area. Consequently, a simple random sampling method was used for obtaining 7 soil samples to laboratory experiments. These soil samples obtained from the top soil $(5 \mathrm{~cm})$ of each sample sites. Subsequently, obtained 1.00 grams from each 7 soil samples. Put the 1 gram of soil sample into a titration flask and added $10 \mathrm{ml}$ of potassium dichromate $\left(\mathrm{K}_{2} \mathrm{Cr}_{2} \mathrm{O}_{7}\right)$ into the sample. After support to the reaction added $20 \mathrm{ml}$ of concentrated Sulfuric acid $\left(\mathrm{H}_{2} \mathrm{SO}_{4}\right)$ in portion wise. The mixture was mixed thoroughly and allowed to stand for 30 minutes for the reaction to be completed. After the mixture was diluted with distilled water $(200 \mathrm{ml})$ to minimize the error/ minimize the intensity of color. And added $10 \mathrm{ml}$ of Phosphoric acid $\left(\mathrm{H}_{3} \mathrm{PO}_{4}\right)$. The solution was mixed and diphenylamine indicator $(1.0 \mathrm{ml})$ was added to the flask. This solution was titrated with standard ferrous ammonium Sulphate to a brilliant green color (Figure 01). After calculating the soil organic carbon percentage using following formula.

$$
\text { Carbon } \%=\frac{\mathrm{NFeSO} 4 \times(\mathrm{V} 1-\mathrm{V} 2) \times 0.39}{\text { Soil grams }}
$$

\section{Results}

Usually, the surface layer has the highest level of SOC and it decrease with depth down the soil profile. Globally, clearing natural vegetation for agriculture results in large reductions in SOC levels and further declines may occur due to management practices (Chan, 2008). Study area also have several land use patterns and the results revealed that SOC in study area have decreased parallel to the scrubs area.

Table 1: SOC percentage in soil samples

\begin{tabular}{|l|c|}
\hline Soil Samples sites & SOC $(\%)$ \\
\hline Scrub & 1.82 \\
\hline Brick Industry & 0.26 \\
\hline Sand mining industry & 0.33 \\
\hline Crop cultivation & 1.43 \\
\hline Paddy cultivation & 0.78 \\
\hline Home garden & 1.25 \\
\hline Vegetable cultivation & 1.39 \\
\hline
\end{tabular}

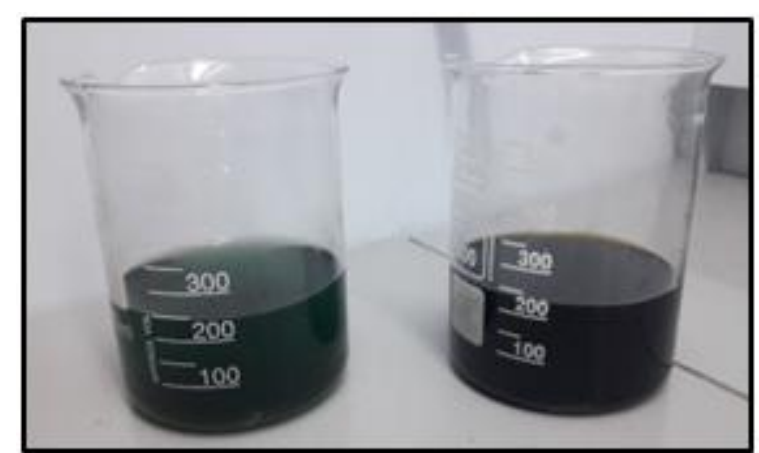

Figure 1: Titrated with standard ferrous ammonium Sulphate

(Source: Compiled by author according to the results of laboratory experiments, 2019)

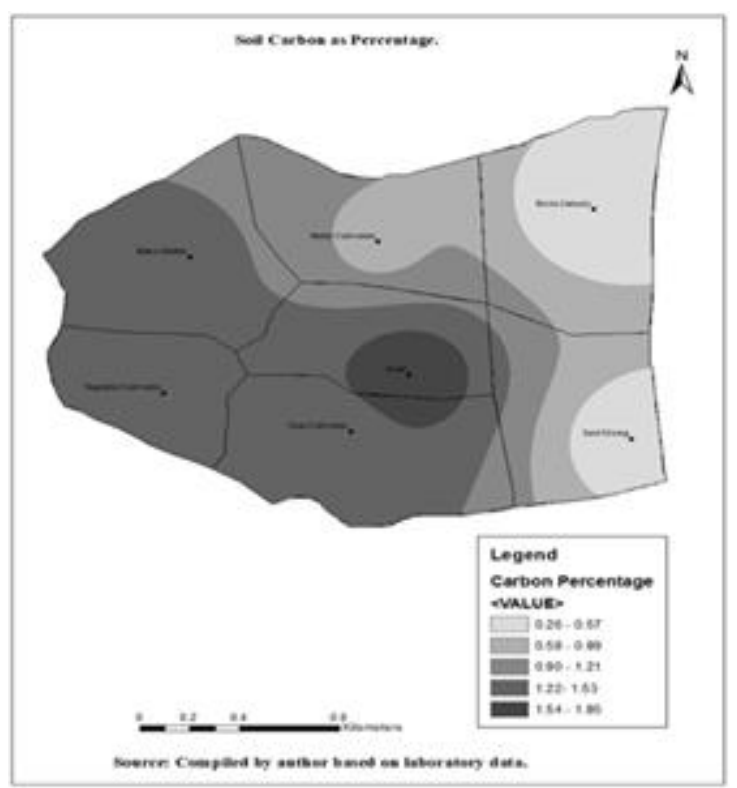

Figure 2: SOC \% in the study area

(Source: Laboratory experiments, 2019)

According to Common wealth Scientific and Industrial Research Organization (CSIRO) has been mentioned in rain - forest or good soils, soil organic carbon can be greater than $10 \%$, while poorer or heavily exploited soils, levels are likely to be less than $1 \%$. According to the study of Yin Chan in 2008 has been estimated that soil carbon levels have dropped by up to $50 \%$ compared to pre agricultural periods in Australia. Most of the reduction in SOC occurs in the surface soil layer, $0-10 \mathrm{~cm}$. Therefore, soil carbon levels of agricultural soils are lower than corresponding soils under 
natural vegetation. Table 01 results also proved above statement clearly.

Soil organic carbon plays an important role in the stability, fertility and health of soil. The percentage of organic carbon is high in scrub areas in We were GND. It is $1.82 \%$ (Table 01). But the lowest carbon percentage in the area represented in brick industry. It represented as $0.26 \%$. This feature can also be identified in the case of sand mining industry. It also represents $0.33 \%$ of SOC. overgrazing, use machinery to soil loosening are affected to SOC in these area.

Also noticeable in the study area is the low carbon in paddy lands. The paddy fields in the area are rich in phosphate and very low in SOC percentage due to the excessive chemical fertilizer. Farmers do not follow the standards of Department of Agriculture, Sri Lanka. Excessive ploughing methods, water supply methods in paddy fields are reducing the SOC in the study area. Today, machinery is widely used to reduce time, reduce manpower, and increase yields in the study area. As a result, soil erosion has accelerated and top soil layer washed away. Due to that SOC also decrease in the area.

Due to the several management practices, such as cultivation, stubble burning or removal, overgrazing, excessive tillage, weeding methods, encroachment of scrubs area has reduced SOC in the study area. The results indicated that scrub area has more SOC than the other land use patterns in the area. It caused to the soil health in the rural agricultural area in Sri Lanka.

\section{Recommendations}

Retention of soil organic carbon (SOC) is very important to protect soil health and to gain agricultural benefits. Although it can help to mitigate climate change. Soil fertility enhancement is important management practice to increase SOC in the soil. Although conservation farming is best practice to it. Introduce stubble retention, reduce tillage, zero tillage, crop rotation, control soil erosion, fertilizer management, weed control methods, grazing management, introduce earthworm, improve grass species, introduction of legumes, introduction of perennial pastures are some management practices to increase the soil organic carbon in the soil. Further use of organic amendment such as plant debris, animal manures are dominant method to increase SOC in soil. They are all high in organic carbon and therefore represent additional carbon inputs to the soil. In addition, land use conservation from cropland to its natural vegetation improves SOC in soil.

People in rural agricultural area are not aware about the soil health and management practices to increase the soil organic carbon. Although they do not aware about the results of loss of SOC in the soil. Consequently, they have done several unsuitable practices and it caused to loss of SOC in the study area. Hence public awareness is the best solution to this problem. Introduce practical programs, awareness programs are best methods to aware the farmers.

\section{Conclusion}

Soil organic carbon as a sink for atmospheric carbon. Soil carbon sequestration is very important to alleviate the problem of global warming and climate change. Further it is very important component of the global carbon cycle. It is the largest component of the terrestrial carbon pools, approximately twice the amount of carbon in the atmosphere and in vegetation. If more carbon is stored in the soil as organic carbon, it will reduce the amount present in the atmosphere. Further this study highlighted rural agricultural areas in Sri Lanka have variation of SOC in the soil due to several land use patterns. So these dynamic features caused to land degradation problems such as erosion and soil structural decline. Finally, it causes to the decline of soil health and productivity of agricultural lands. Due to that it is very important to increase SOC in the soil. Because SOC is the best indicator to soil health.

\section{References}

[1] Brown, D. J., Shepherd, K. D., Walsh, M. G. (2006). Global soil characterization with VNIR diffuse reflectance spectroscopy, Geoderma.132: 273-290. doi: $10.1016 /$ j. geoderma.

[2] Chan, Y. (2008). Increasing soil organic carbon ofagricultural land, Profitable and sustainable prime industry.

[3] Don, A., Schumacher, J., Freibauer, A. (2011). Impact of tropicalland - use change on soil organic carbon stocks - a meta - analysis. Glob Change Biol 17: 16581670. doi: 10.1111/j.1365 2486.2010.02336. x

[4] FAO and ITPS. (2015). Status of the World's Soil Resources (SWSR) - Main Report. Food and Agriculture Organization of the United Nations and Intergovernmental Technical Panel on Soils, Rome, Italy.

[5] FAO and UNEP. (2021) Global assessment of soil pollution - Summary for policy makers. Rome, FAO. https: //doi. org/10.4060/cb4827en.

[6] Huber, S., Syed, B., Freudenschuss, A., Ernstsen, V., and Loveland. (2001) Proposal for a European soil monitoring and assessment framework. Technical report no.61, European Environment Agency, Copenhagen, Denmark

[7] Kendaragama, K. M. A., (2010), Policies on mitigation of land degradation in Sri Lanka, Minisrty of Environment and Renewable energy, Battaramulla, Sri Lanka.

[8] Lehmann, J., Bossio, D. A., Kögel - Knabner. (2020) The concept and future prospects of soil health. Nat Rev Earth Environ 1, 544-553. https: //doi. org/10.1038/s43017 - 020 - 0080 - 8.

[9] Mapa, R. B., Somasiri, S., Dassanayake, A. R., (2010), Soils of dry zone of Sri Lanka, Soil science society of Sri Lanka, SarvodayaVishwaLekha publishers.

[10] Mapa, R. B., Dassanayake. A. R., Nayakekorale, H. B., (2005), Soils of the Intermediate zone of Sri Lanka, Soil science society of Sri Lanka, SarvodayaVishwaLekha publishers.

[11] Ngatia, L. W., Moriasi, D., Grace, J. M., Riqiang Fu, Gardner, C. S., Taylor, R. W. (2021) Land Use Change Affects Soil Organic Carbon: An Indicator of Soil 
Health, Physical Sciences, Engineering and Technology. DOI: 10.5772/intechopen.95764.

[12] Pankhurst, C. E., Gregorich, E. G., Carter, M. R., Doran, J. W., Dwyer, L. M. (1997). Biological attributes of soil quality.25: $81-113$.

[13] Salinas - Garcia, J. R., Hons, F. M., Matocha, J. E., Zuberer, D. A. (1997). Soil carbon and nitrogen dynamics as affected by long - term tillageand nitrogen fertilization. Biol. Fert. Soils, 25: 182-188.

[14] Tiessen, H., Cuevas, E., Salcedo, I. H. (1998). Organic matter stabilityand nutrient availability under temperate and tropical conditions. In: Blume HP, et al. (eds.), Towards Sustainable Land Use. Advances in GeoEcology, Catena Verlag, Reiskirchen, Germany, pp.415-422.

[15] Vanlauwe, B., Descheemaeker, K., Giller, K. E. (2014) Integrated soil fertility management in sub - Saharan Africa: unravelling local adaptation. Soil Discuss 1: 1239-1286. doi: 10.5194/soild - 1 - 1239 - 2014.

[16] Winowiecki, L., Vagen, T., Massawe, B., Jelinski, N. A., Lyamchai, C., Sayula, G., Msoka, E. (2016) Landscape - scale variability of soil health indicators: effects of cultivation on soil organic carbon in the Usambara Mountains of Tanzania, Nutrient Cycling in Agroecosystems, 105: 263-274, DOI 10.1007/s10705 $015-9750-1$. 